\title{
Sol-gel synthesis of novel photosensitive material with advanced holographic properties
}

\author{
Go KAWAMURA ${ }^{\dagger}{ }^{\dagger}$ Yuki TSURUMI, Hiroyuki MUTO, Mitsuteru INOUE and Atsunori MATSUDA
}

Department of Electrical and Electronic Information Engineering, Toyohashi University of Technology,

1-1 Hibarigaoka, Tempaku-cho, Toyohashi, Aichi 441-8580

\begin{abstract}
Silver chloride nanoparticle-doped glycidoxypropylsilsesquioxane-titania hybrid films are prepared by the sol-gel method and their hologram-related properties are investigated. The optical absorption of the film embedded with AgCl nanoparticles at a blue laser wavelength is stronger than that of the film embedded with $\mathrm{AgBr}$ nanoparticles. The strong absorption of the film with AgCl nanoparticles leads to a considerable increase in absorption in the visible wavelength region upon blue laser irradiation. This phenomenon is generally implicated in good hologram formation ability of the film. A simultaneous addition of $\mathrm{AgNO}_{3}$ and $\mathrm{CCl}_{3} \mathrm{COOH}$ from separate vessels to the sol realizes homogeneous dispersion of $\mathrm{AgCl}$ in the hybrid films. The diffraction efficiency of the film exposed to an interferential blue laser shows a good hologram formation ability of the film and a high reliability for readout-angle deviation.
\end{abstract}

(C2011 The Ceramic Society of Japan. All rights reserved.

Key-words : Sol-gel, Silver chloride, Silver nanoparticles, Surface plasmon resonance, Hologram

[Received February 9, 2011 ; Accepted March 25, 2011]

\section{Introduction}

Holographic materials have been studied for their applications to security printing, 3-dimensional display, data storage, and so on. ${ }^{1), 2)}$ Among the materials studied so far, photopolymers and silver halide films are promising candidates for use in holography because of their high sensitivity to visible laser irradiation and high spatial resolution. ${ }^{3), 4)}$ However, there are several problems with these materials, including low durability, shrinkage, swelling, irreversibility, complexity of hologram formation, etc. ${ }^{5)}$

The essential properties required for holographic materials are, for example, sensitivity to visible light, narrow reaction region, homogeneity, reversibility, and durability. The inorganic-organic hybrids prepared by the sol-gel method are promising host matrices to design such holographic materials. ${ }^{6}$ In order to materialize promising holographic material, we have prepared $\mathrm{Ag}^{+}$ion- or $\mathrm{AgBr}$ nanoparticle-doped inorganic-organic hybrid films by the sol-gel method and evaluated their optical properties including the hologram formation ability. The mechanism of the hologram formation in the films is the generation of $\mathrm{Ag}$ nanoparticles at the region where strong light is irradiated. The Ag nanoparticles exhibit surface plasmon resonance (SPR); the periodic existence of which is recognized as hologram. The $\mathrm{Ag}^{+}$ ion-doped films, in fact, showed sufficient homogeneity, reversibility, and durability for the practical use as holographic materials. ${ }^{7)}$ Sensitivity to visible light was further given to the films by bromination of $\mathrm{Ag}^{+}$ions, whereas the homogeneity and reversibility were deteriorated. ${ }^{8)}$

In this work, we found that the change of the halogen element from $\mathrm{Br}$ to $\mathrm{Cl}$ was very effective to improve reactivity upon visible light irradiation. The film preparation procedure was also refined to obtain better homogeneity, leading to a narrower reaction region for the hologram formation.

Corresponding author: G. Kawamura; E-mail: gokawamura@ ee.tut.ac.jp

\section{Experimental procedure}

Silver chloride-doped glycidoxypropylsilsesquioxane-titania $\left(\mathrm{AgCl}: \mathrm{GPSiO}_{3 / 2}-\mathrm{TiO}_{2}\right)$ films were prepared by the sol-gel technique using 3-glycidoxypropyltrimethoxysilane [ $\mathrm{GPSi}(\mathrm{OMe})_{3}$, Shin-Etsu], titanium tetra- $n$-butoxide [Ti(O- $n$-Bu $)_{4}$, Wako], silver nitrate $\left(\mathrm{AgNO}_{3}\right.$, Wako) and trichloroacetic acid $\left(\mathrm{CCl}_{3} \mathrm{COOH}\right.$, Wako). Because the samples are photosensitive, the experiments were carried out in the dark. To prepare the $\mathrm{AgCl}: \mathrm{GPSiO}_{3 / 2}-\mathrm{TiO}_{2}$ sol, GPSi(OMe $)_{3}$ in ethanol was hydrolyzed by the simultaneous addition of $\mathrm{AgNO}_{3}$ dissolved in aqueous $\mathrm{HNO}_{3}$ and $\mathrm{CCl}_{3} \mathrm{COOH}$ dissolved in $\mathrm{H}_{2} \mathrm{O}$, or by the addition of premixed $\mathrm{AgNO}_{3}$ and $\mathrm{CCl}_{3} \mathrm{COOH}$ in aqueous $\mathrm{HNO}_{3}$, then stirred for $0.5 \mathrm{~h}$. Ti $(\mathrm{O}-n-\mathrm{Bu})_{4}$ modified with ethyl acetoacetate (EAcAc, Wako) was then added to the partially hydrolyzed $\mathrm{GPSi}(\mathrm{OMe})_{3}$ solution. The molar ratio of GPSi(OMe $)_{3}: \mathrm{Ti}(\mathrm{O}-n-\mathrm{Bu})_{4}: \mathrm{EAcAc}: \mathrm{EtOH}: \mathrm{H}_{2} \mathrm{O}\left(1.2 \mathrm{mM} \mathrm{HNO}_{3}\right)$ : $\mathrm{AgNO}_{3}: \mathrm{CCl}_{3} \mathrm{COOH}$ was $8: 2: 0.5: 50: 50: 3: 1.5$. The solution was stirred at room temperature for $1 \mathrm{~h}$ to allow further hydrolysis of $\mathrm{GPSi}(\mathrm{OMe})_{3}$ and $\mathrm{Ti}(\mathrm{O}-n-\mathrm{Bu})_{4}$. The $\mathrm{AgCl}: \mathrm{GPSiO}_{3 / 2}-\mathrm{TiO}_{2}$ film was formed on a non-alkaline glass plate (AvanStrate NA35) by dip-coating the glass plate in the prepared sol with a withdrawal speed of $20 \mathrm{~mm} / \mathrm{s}$, giving a film thickness of ca. $5 \mu \mathrm{m}$. The dipcoated film was dried at room temperature overnight.

The optical properties of the films before and after blue laser irradiation $\left(405 \mathrm{~nm}, 10 \mathrm{~mW} / \mathrm{cm}^{2}, 10 \mathrm{~min}\right)$ were investigated using an ultraviolet-visible (UV-Vis) spectrophotometer (Jasco $\mathrm{V}-560)$. Structural analyses of the films were performed with an X-ray diffraction (XRD, Rigaku RINT-2000, $\mathrm{CuK} \alpha$ ) and a transmission electron microscopy (TEM, JEOL JEM-2100F). The TEM samples for the cross sectional observation were prepared by using a focused-ion beam equipment (FIB, FEI Quanta 3D) with a surface pre-sputtering using Pt. The dynamics of the diffraction efficiency (DE) of the films during two-beam interference exposure using a blue laser $\left(402 \mathrm{~nm}, 3 \mathrm{~mW} / \mathrm{cm}^{2}\right)$ was studied by simultaneous probing of the recorded interference fringes using a red laser $(633 \mathrm{~nm})$. The handmade DE measure- 


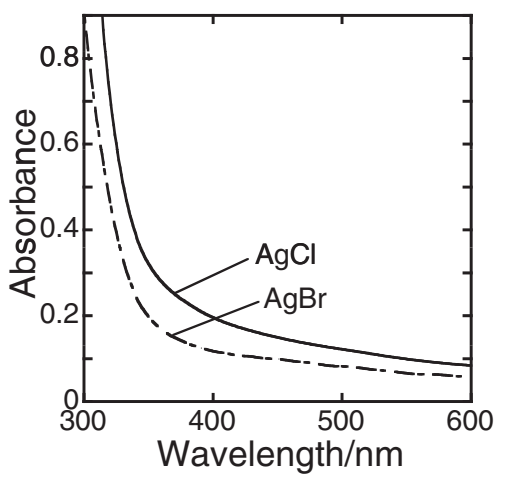

Fig. 1. UV-Vis absorption spectra of the $\mathrm{AgCl}$ and $\mathrm{AgBr}$ nanoparticledoped $\mathrm{GPSiO}_{3 / 2}-\mathrm{TiO}_{2}$ hybrid films.

ment system is described in our previous paper. ${ }^{8)}$ The DE in this study was defined as the diffracted light intensity (first order) divided by the transmitted light intensity.

\section{Results and discussion}

\subsection{Absorption change}

We have revealed that hologram can be recorded in the $\mathrm{AgBr}$ nanoparticle-doped $80 \mathrm{GPSiO}_{3 / 2} \cdot 20 \mathrm{TiO}_{2}$ hybrid film by interference exposure using a blue laser. ${ }^{8)} \mathrm{AgBr}$, however, possesses quite low solubility in water, so that the $\mathrm{AgBr}$ nanoparticles easily grew larger in the sol, resulting in the difficulty in the homogeneous dispersion of $\mathrm{AgBr}$ in the dip-coated film. Moreover, such large particles could not be involved in the formation of film by dip-coating method, thus the film composition was sometimes not equal to the nominal one. These resulted in the weakened optical absorption of the film, leading to low quantum efficiency on hologram formation by blue laser irradiation. In this work, $\mathrm{Cl}$ was selected to form silver halide nanoparticles in the hybrid films. The solubilities of $\mathrm{AgBr}$ and $\mathrm{AgCl}$ are $5.0 \times 10^{-13}$ and $1.8 \times 10^{-10}$, respectively. In the case of $\mathrm{AgCl}$, the abrupt formation of large particles in the sol can be suppressed, and homogeneous dispersion of $\mathrm{AgCl}$ with the nominal composition in the film should be achieved. This results in the efficient absorption of photons by the prepared film samples. Figure 1 shows the UV-Vis absorption spectra of the $\mathrm{AgCl}$ and $\mathrm{AgBr}$ nanoparticle-doped $\mathrm{GPSiO}_{3 / 2}-\mathrm{TiO}_{2}$ hybrid films. Although the band gap of $\mathrm{AgCl}(3.25 \mathrm{eV})$ is larger than that of $\mathrm{AgBr}(2.70 \mathrm{eV})$, the absorbance of $\mathrm{AgCl}$-doped film is apparently larger than that of $\mathrm{AgBr}$-doped one in the whole measured wavelength region. This is due to higher homogeneity of the AgCl-doped sol as mentioned above, i.e., well-dispersed, highly concentrated $\mathrm{AgCl}$ nanoparticles exist in the film instead of formation of the large particles leading to the precipitation in the sol, and segregation of the particles in the film. Figure 2 shows the UV-Vis absorption spectra of the $\mathrm{AgCl}$-doped film before and after blue laser irradiation for $10 \mathrm{~min}$. The blue laser irradiation caused the absorption increase in the whole visible wavelength region. This is probably because the $\mathrm{AgCl}$ nanoparticles absorb energy of blue laser and are photo-reduced to Ag nanoparticles which exhibit SPR in the visible region. The absorption intensity increment in the $\mathrm{AgCl}$-doped film upon the irradiation of the constant quantity of the photons was several times larger than that in the AgBrdoped film. This supports an assumption that the photon absorption by silver halide nanoparticles induces the absorption increase by blue laser irradiation in the visible wavelength region. The absorption change of the film is the main phenomenon for the amplitude hologram formation. ${ }^{9)}$

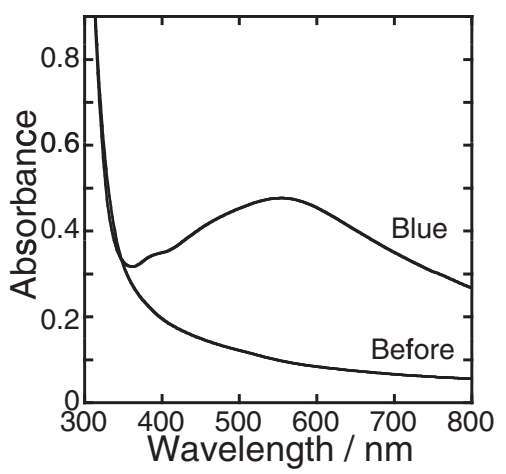

Fig. 2. UV-Vis absorption spectra of the AgCl-doped film before and after blue laser irradiation.

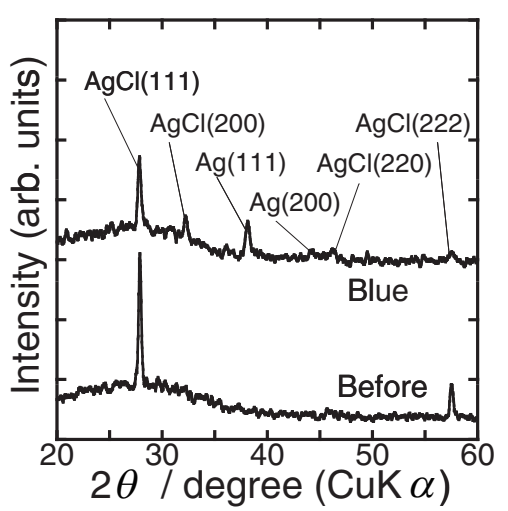

Fig. 3. XRD patterns of the AgCl-doped film before and after blue laser irradiation.

\subsection{Structural analysis}

Figure 3 shows the XRD patterns of the AgCl-doped film before and after blue laser irradiation. The film before blue laser irradiation showed only the diffraction peaks of $\mathrm{AgCl}$. Since the peaks from (111) and (222) planes of $\mathrm{AgCl}$ face-centered cubic structure were observed, it was found that the crystals were oriented in a specific direction in the film. This phenomenon is sometimes observed when nanoparticle-dispersed sol-gel-derived film is synthesized via the dip-coating process. This orientation of the nanoparticles in the film is generally explained by the generation of mechanical stress during the dip-coating process. ${ }^{10), 11)}$ On the other hand, the film after blue laser irradiation showed the diffraction peaks of $\mathrm{Ag}$ in addition to those of $\mathrm{AgCl}$. This also supports that the absorption increase by blue laser irradiation observed in Fig. 2 is caused by the formation of $\mathrm{Ag}$ nanoparticles which exhibit SPR in the visible wavelength region. The peaks from unoriented $\mathrm{AgCl}$ crystals were also detected. Table 1 shows the crystalline sizes in the films before and after blue laser irradiation, calculated by using Scherrer equation. It was revealed that the blue laser irradiation caused a decrease in crystalline size of $\mathrm{AgCl}$ calculated by (111) peaks of $\mathrm{AgCl}$. The peak area of $\mathrm{AgCl}(111)$ evaluated from XRD pattern in Fig. 3 was also decreased by blue laser irradiation. The crystalline size of $\mathrm{Ag}$ formed by the blue laser irradiation was estimated from $\operatorname{Ag}(111)$ peak to be ca. $30 \mathrm{~nm}$. These indicated that the blue laser irradiation caused the dissociation of oriented $\mathrm{AgCl}$ nanoparticles, resulting in the formation of $\mathrm{Ag}$ nanoparticles. At the same time, some of the adjacent $\mathrm{Ag}$ and $\mathrm{Cl}$ would be able to recombine and form unoriented new $\mathrm{AgCl}$ crystal in the film. 
Table 1. Crystalline sizes of $\mathrm{AgCl}$ and $\mathrm{Ag}$ in the films before and after blue laser irradiation, calculated from their XRD patterns shown in Fig. 3

\begin{tabular}{ccc}
\hline \multirow{2}{*}{ Crystal } & \multicolumn{2}{c}{ Size $/ \mathrm{nm}$} \\
\cline { 2 - 3 } & Before & Blue \\
\hline $\mathrm{AgCl}$ & 48 & 40 \\
$\mathrm{Ag}$ & - & 30 \\
\hline
\end{tabular}

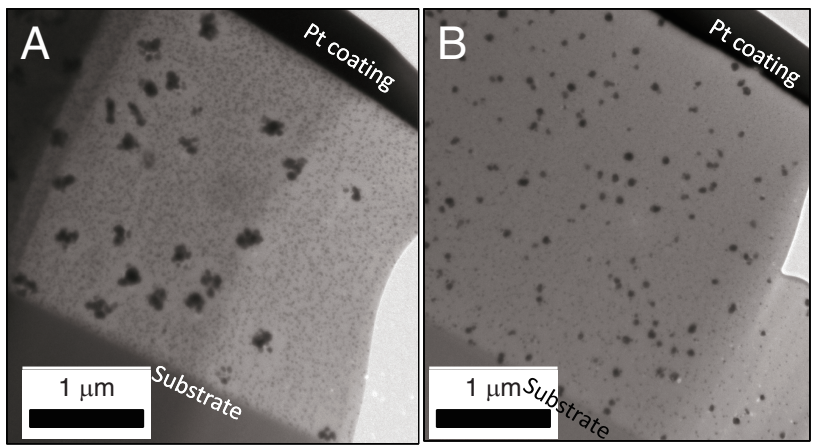

Fig. 4. Cross-sectional TEM images of the AgCl-doped films prepared by previous (A) and new procedures (B).

\subsection{Spatial resolution improvement}

The average sizes of $\mathrm{AgCl}$ and $\mathrm{Ag}$ crystallites in the film were $30-50 \mathrm{~nm}$ as shown in Table 1. Since high precision of hologram recording and reading strictly requires the fringe formation which perfectly reflects the electric field created by interference exposure using a blue laser in the film, the spatial resolution of the holographic material, i.e., narrowness of hologram formation reaction region is essential for the holographic performance. ${ }^{12)}$ From the average size calculated, the $\mathrm{AgCl}$ nanoparticles would be too large to form ultrafine hologram in the film by blue laser irradiation. Thus, the sol preparation procedure was modified to improve the spatial resolution. In the modified procedure, $\mathrm{AgNO}_{3}$ and $\mathrm{CCl}_{3} \mathrm{COOH}$ in separate vessels were simultaneously added to the sol including $\mathrm{GPSi}(\mathrm{OMe})_{3}$ and ethanol. Figure 4 shows the cross-sectional TEM images of the AgCl-doped films prepared by the previous method which uses the premixed solution of $\mathrm{AgNO}_{3}$ and $\mathrm{CCl}_{3} \mathrm{COOH}$ in a vessel (A), ${ }^{8)}$ and by above mentioned newly modified method (B). Both films were irradiated with blue laser before the TEM observation. The film prepared by the previous method (A) contained crooked nanoparticles with a diameter of ca. $100 \mathrm{~nm}$ as well as very small ones with a diameter of less than $20 \mathrm{~nm}$. All these nanoparticles were defined as $\mathrm{Ag}$ nanoparticles by high-resolution TEM and electron diffraction. As shown in Fig. 3, $\mathrm{AgCl}$ remains and coexists with $\mathrm{Ag}$ in the film even after blue laser irradiation. However, the remained $\mathrm{AgCl}$ nanoparticles dissociated upon electron beam irradiation (EBI) to form $\mathrm{Ag}$ nanoparticles without significant changes in the size and morphology, where this EBI-induced conversion of $\mathrm{AgCl}$ to $\mathrm{Ag}$ nanoparticles was confirmed by the time-resolved TEM observation. The existence of bigger nanoparticles with a diameter of ca. $100 \mathrm{~nm}$ influences the precise formation of hologram in the film. Namely, in the case that the big nanoparticles with a diameter of ca. $100 \mathrm{~nm}$ stand at the interface between strong and weak electric fields (average interval: $\sim 200 \mathrm{~nm}$ ) created by the interference exposure using a blue laser, the formation of hologram reflecting precisely the electric fields is hampered. On the other hand, the film prepared
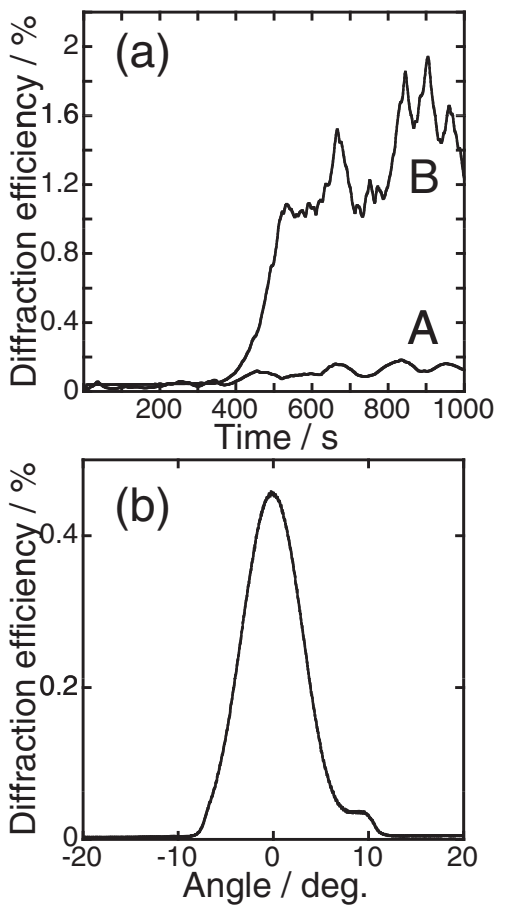

Fig. 5. Dynamics of DE of the AgCl-doped films prepared by the previous (A) and new procedures (B) during the two-beam interference exposure using a blue laser (a), and variation in DE of the film prepared by the new procedure as a function of the angle between the proving red laser and sample (b).

by the new procedure contained only $\mathrm{Ag}$ nanoparticles with a diameter of less than $40 \mathrm{~nm}$ [see Fig. 4(B)]. This was probably caused by the separate addition of $\mathrm{AgNO}_{3}$ and $\mathrm{CCl}_{3} \mathrm{COOH}$, which suppressed the deposition of $\mathrm{AgCl}$ nanoparticles at the early stage of sample preparation procedure and the growth of the $\mathrm{AgCl}$ nanoparticles in the sol. This was confirmed by observing the appearance of the sols, where the sol prepared by the new procedure was transparent throughout the process whereas the other became translucent by addition of the premixed solution. Although the optical absorption spectra of the films prepared by the different procedures were not expressively different regardless of the implementation of blue laser irradiation, the spatial resolution of the film is presumably drastically improved by applying this new sample preparation procedure, thus the high DE is expected. Moreover, the photosensitivity of the films was little different. This was checked by measuring the changes in optical absorption of the films after blue laser irradiation with various laser powers.

\subsection{DE evaluation}

The DE, i.e., the hologram formation ability was evaluated using handmade instrument which performs writing of holographic fringes using a blue laser and simultaneous readout of the formed fringes using a red laser. Figure 5(a) shows the dynamics of $\mathrm{DE}$ of the $\mathrm{AgCl}$-doped films prepared by two different procedures during the two-beam interference exposure using a blue laser. Although the DE of the film prepared by the previous method was very low $\left(\mathrm{DE}_{\max }=0.15 \%\right)$, the $\mathrm{DE}$ of the other one started to increase after laser irradiation for $400 \mathrm{~s}$, and kept the value larger than $1 \%$ on and after $500 \mathrm{~s}$. The $>1 \%$ DE is relatively high (ca. one third of theoretical maximum value) as an amplitude hologram, and for example, it is sufficient for the 
practical application to hologram data storage medium. This value is also quite high compared with the value obtained from AgBr-doped film $\left(\mathrm{DE}_{\max }=0.03 \%\right){ }^{8)}$ The obtained high $\mathrm{DE}$ is presumably due to the following two points: (i) the increased absorption at $405 \mathrm{~nm}$ by substituting $\mathrm{Br}$ for $\mathrm{Cl}$, (ii) the improved spatial resolution of the film by adding $\mathrm{AgNO}_{3}$ and $\mathrm{CCl}_{3} \mathrm{COOH}$ at the same time from the separate vessels instead of adding premixed $\mathrm{AgNO}_{3}$ and $\mathrm{CCl}_{3} \mathrm{COOH}$ solution to the sol. Figure 5(b) shows the variation in the DE of the film prepared by the new method as a function of the angle between the proving red laser and sample. The angle where the maximum DE was obtained was set at $0^{\circ}$. Since high DE was obtained in the wide angle region between 5 and $-5^{\circ}$, the readout reliability of recorded hologram in the film was recognized as sufficiently high. The improvement for the recording rate and rewritability of hologram requested for the practical use are now under investigation.

\section{Conclusions}

The sol-gel-derived $\mathrm{AgCl}$ nanoparticle-doped $\mathrm{GPSiO}_{3 / 2}-\mathrm{TiO}_{2}$ hybrid films were prepared and tested whether they possessed sufficient sensitivity to blue laser irradiation and spatial resolution for the application to holographic materials. Blue laser irradiation $\left(405 \mathrm{~nm}, 10 \mathrm{~mW} / \mathrm{cm}^{2}, 10 \mathrm{~min}\right)$ caused absorption increase in the visible wavelength region, resulting from the photo-dissociation of $\mathrm{AgCl}$ and the formation of $\mathrm{Ag}$ nanoparticles which exhibit SPR. The spatial resolution of the film was improved by the slight modification of the sample preparation procedure, where $\mathrm{AgNO}_{3}$ and $\mathrm{CCl}_{3} \mathrm{COOH}$ were separately added. This resulted in the significant improvements of DE $(>1 \%)$ and angle deviation reliability $\left( \pm 5^{\circ}\right)$ of the formed hologram.
Acknowledgments This work was supported by Grants-in-Aid for Young Scientists (Start-up) 21860045, Young Scientists (B) 22760539, and Scientific Research (B) 20360298 from the Japan Society for the Promotion of Science (JSPS). This was also partly supported by Nanophotonics Information Technology Center (NAIT) in Toyohashi University of Technology.

\section{References}

1) T. J. Trout, J. J. Schmieg, W. J. Gambogi and A. M. Weber, Adv. Mater., 10, 1219-1224 (1998).

2) T. Y. Kim, T. Hirano, Y. Yamazaki and M. Abe, Phys. Status Solidi, 201, 1759-1762 (2004).

3) V. Colvin, R. Larson, A. L. Harris and M. Schilling, J. Appl. Phys., 81, 5913-5923 (1997).

4) L. Dhar, A. Hale, H. E. Katz, M. L. Schilling, M. G. Schnoes and F. C. Schilling, Opt. Lett., 24, 487-489 (1999).

5) F. Ortuño, E. Fernández, S. Gallego, A. Beléndez and I. Pascual, Opt. Express, 15, 12425-12435 (2007).

6) A. Matsuda, T. Sasaki, K. Tadanaga, M. Tatsumisago and T. Minami, Chem. Mater, 14, 2693-2700 (2002).

7) G. Kawamura, S. Sato, T. Kogure, Y. Daiko, H. Muto, M. Sakai and A. Matsuda, Phys. Chem. Chem. Phys., 12, 6859-6863 (2010).

8) G. Kawamura, S. Sato, H. Muto, M. Sakai, P. B. Lim, K. Watanabe, M. Inoue and A. Matsuda, Mater. Lett., 64, 2648-2651 (2010).

9) T. Koskinen, Doctoral Thesis, Helsinki University of Technology Radio Laboratory, Espoo, Finland (2007).

10) J. Y. Tseng, C. Y. Li, T. Takada, C. Lechner and J. D. Mackenzie, Proc. SPIE, 1758, 612-620 (1992).

11) M. Zayat, D. Einot and R. Reisfeld, J. Sol-Gel Sci. Technol., 10, 67-74 (1997).

12) Y. Ohe, H. Ito, N. Watanabe and K. Ichimura, J. Appl. Polym. Sci., 77, 2189-2200 (2000). 